\title{
Effects of Fillerwire Composition along with Different Pre- and Post-Heat Treatment on Mechanical Properties of AISI 4130 Welded by the GTAW Process
}

\author{
Ali Emamian ${ }^{1}$, Ardalan Emamian ${ }^{2}$, Amir Hossein Kowkabi ${ }^{3}$ \\ ${ }^{1}$ Department of Mechanical and Mechatronics Engineering, University of Waterloo, Waterloo, Canada; ${ }^{2}$ Department of Mechanical \\ Engineering, IAU, Esfahan, Iran; ${ }^{3}$ Department of Material Science and Engineering, Sharif University of Technology, Tehran, Iran. \\ Email: aemamian@engmail.uwaterloo.ca
}

Received May $8^{\text {th }}, 2010$; revised May $31^{\text {st }}, 2010$; accepted June $8^{\text {th }}, 2010$.

\begin{abstract}
This research intends to find out the optimal mechanical properties of AISI 4130 steel welded by the GTAW process. Six test plates were joined by two types of filler wire with similar chemical composition to the base metal, and with lower carbon content and slightly higher alloy elements content compared to the first one. Test plates then exerted three different pre-heat and post-heat treatments on both groups. The three types of heat treatments were alternatively without pre-heat and post-heat, with pre-heat only, and finally with pre-heat and post-heat. Tensile, side bends and impact tests (for weld zone and HAZ) have been conducted. Results show that using low-carbon filler wire along with pre- and post-heat resulted in outstanding mechanical properties.
\end{abstract}

Keywords: HAZ (Heat Affected Zone), Filler Wire, Pre- and Post-heat Treatments, GTAW Process

\section{Introduction}

The unending search for novel mechanical properties has led to significant development in material with high strength. The 4130 grade of chrom-moly is in the HSLA group of steel. Although 4130 is not lighter than general steels, its higher specific strength ratio enables the engineers to reduce the weight of designs by using thinner thicknesses. Having ductility and specific strength at the same time increases the applications of 4130 in the aerospace, machinery, and motor sports industries.

The sensitivity of high-strength and ultra-high-strength steel to the welding, increases the need to investigate the weld ability and mechanical properties of these types of steel. In the welding process the heat affected zone is heated above its critical temperature (A3 or Acm). On the other hand, the cooling rate of steel affects its microstructure and constructs different phases. According to the chemical composition of AISI4130 (Table 1), due to its hardness and CCT diagram, it is probable to have ferriticperlitic, ferritic-bainaitic or martensitic structure. Consequently, different microstructures result in different mechanical properties.
During the welding process, mechanical properties of weld joints can drop dramatically $[1,2]$. Bevis and Fulcer et al. provide information about welding of 4130 tubes with thicknesses less than $1 / 8$ inches. Todd et al. studied tube welding and technical issues of 4130 [3,4]. Earolino et al. studied the effect of carbon content and alloy elements on maximizing the hardness of liquid boundaries [5]. They observed an increase in the hardness of weld metal and the liquid boundary. Changing the chemical composition by filler wire and dilution does not affect the HAZ in constant welding parameters. Therefore, the afore-mentioned studies do not provide sufficient information about HAZ properties.

Kyte et al. and Hooijmians et al. have investigated hydrogen cracking and hydrogen removal during GTAW welding. They developed a model which shows the relation between hydrogen content and welding parameters $[6,7]$. Still et al. investigated the necessary conditions for cold cracking and the forming of bainite or martensite [8].

In the past decade, a considerable portion of the literature has focused on technical aspects or advanced technology devices such as laser or electron beam welding to 
study fatigue, crack growth or residual stress on 4130 [9].

Fatigue is a complex phenomenon compared to tensile, impact or bending properties. Without complete understanding of a material's behavior in tensile, impact or bending tests, dynamic test results are difficult to interpret. Also using lasers or other advanced devices is not always an option in many cases due to their exorbitant cost.

Ravi et al. have studied the effect of post weld heat treatment on estimated fracture toughness. They assert that PWHT does not affect the impact toughness of weld metal [10].

Marcelino et al. have studied the crack growth rate in weld metal, HAZ and base metal in repaired welded joints. They discovered that the fastest fatigue crack growth was in weld metal [11]. Bultel et al. have investigated the effect of temperature on fatigue life considering the phase transformation of ferritic-perlitic and bainitic in 4130 steel [12].

In the welding of 4130 steel, two important factors should be taken into the account: the chemical composition of the weld metal and heat-affected zone mechanical properties. Throughout the literature, no detailed or satisfactory explanation was found regarding controlling weld and HAZ mechanical properties. This lack of data is due in part the majority of published papers being technical reports. Most of the published papers related to this research field can be found in 1980-1997, where HSLA properties generally, either in weld metal or in HAZ, are investigated [13-16]. However, there remains a profound lack of knowledge about the relationship between heat treatment/weld composition and the mechanical properties of AISI 4130 welded parts.

The purpose of this research is to define the optimal condition for welding of 4130 steel with the GTAW process by considering the chemistry of weld metal affected by filler wire and heat treatment simultaneously.

\section{Experimental Method}

AISI 4130 plates sized at $400 \times 200 \times 10 \mathrm{~mm}$ were selected to weld perpendicular to the rolling direction.

To protect the weld pool and focus the weld spot in order to lessen the heat affected zone area, the GTAW process is selected.
Next, a single Vee-Joint is made by the milling machine at an angle of $30^{\circ}$. The number of plates provided is twelve, which results in six test plates after being welded two by two. Three of the six test plates are welded by the filler wire B, whose analysis is like the base metal as presented in Table 3. The remaining test plates are welded by a very low carbon filler wire L (Table 4).

In both cases, the test plates are first welded without pre-/post-heat treatments (prefix 1). Next, the test plates are welded with pre-heat treatments (prefix 2). Finally, the test plates are welded with both pre- and post-heat treatments (prefix 3). In the case studies clarified above, all conditions and welding parameters such as amperage, voltage, argon gas flow (for protection) and welding speed are controlled to be constant. The pre-heat treatment is done by a torch at about $200^{\circ} \mathrm{C}$. At this stage, the temperature is controlled by a thermometer. The inter-pass temperature in all samples is determined to be about $150-250^{\circ} \mathrm{C}$.

In the post-heating treatment, the samples are placed in a furnace with temperature of about $200^{\circ} \mathrm{C}$, which slowly rises to $600^{\circ} \mathrm{C}$. The samples remain at this temperature inside the furnace for about an hour. They are then taken out of the furnace to cool to room temperature. Afterwards, a non-destructive testing process (ultrasonic and radiography) is applied to the samples in order to ensure that the weldments are sound and crack free. The test specimens are cut from the test plates according to AWS D1.1 and ASME SEC 9 standards. The test plates include two tensile, four side bending and six impact test specimens, of which three belong to the weld metal and three to the HAZ. The temperature of the impact tests is decreased to $-50^{\circ} \mathrm{C}$ by alcohol and dry ice.

\section{Results and Discussion}

Table 1 shows the coding system of samples. Micro hardness test results are illustrated in Table 5. Each result is an average of at least five measurements at the same level of weld or heat affected zone. Only the pre and post-heated samples show uniform hardness results in the weld metal and HAZ.

Table 1. Coding system

\begin{tabular}{|c|c|c|c|}
\hline Tensile test & Hardness test & Bending test & Impact test \\
\hline $\mathrm{ABD}$ & $\mathrm{ABD}$ & $\mathrm{ABD}$ & $\mathrm{ABCD}$ \\
\hline \multicolumn{4}{|c|}{$\begin{array}{l}\underline{\mathbf{A}} \text { can be } \mathrm{L} \text { (stands for low carbon, high alloy filler metal) or B (stands for filler metal with same chemical composition as base metal) } \\
\underline{\mathbf{B}} \text { can be } 1 \text { (stands for without pre-/post-heat treatment), } 2 \text { (stands for pre-heat } \\
\text { be treatment) or } 3 \text { (stands for pre- and post-heat treatment samples) } \\
\underline{\mathbf{D}} \text { is sample number } \\
\underline{\mathbf{C}} \text { can W (stands for weld metal) or H (heat affected zone) }\end{array}$} \\
\hline
\end{tabular}


Table 6 shows that the ultimate tensile strength in both types of filler wires decreases when applying both preheat treatments and pre- and post-heat treatments. Preheat resulted in lower cooling rate and retard the formation of brittle and hard phases in weld and HAZ. Moreover, post weld heat treatment decreases the strength by tempering of formed brittle phases which are constructed during the welding process. Generally higher amounts of tensile testing can be observed in samples which are welded by filler metal with higher carbon content (B prefix compared to L). Samples were broken out of the weld and close to the fusion line; hence, a higher amount of carbon in the filler wire B is the main reason for elevated tensile results.

Table 2. Chemical analysis of AISI4130 steel

\begin{tabular}{|c|c|c|c|c|c|c|}
\hline$\% \mathrm{C}$ & $\% \mathrm{Si}$ & $\% \mathrm{~S}$ & $\% \mathrm{P}$ & $\%$ Mn & $\% \mathrm{Ni}$ & $\% \mathrm{Cr}$ \\
\hline 0.25 & 0.23 & 0.003 & 0.010 & 0.49 & 0.088 & 0.91 \\
\hline \%Мо & $\% \mathrm{Cu}$ & $\% \mathrm{Ti}$ & $\% \mathrm{Sn}$ & $\% \mathrm{~V}$ & $\% A \mathbf{A}$ & \\
\hline 0.19 & 0.11 & 0.003 & 0.008 & 0.007 & 0.019 & \\
\hline
\end{tabular}

Table 3. Chemical analysis of high carbon filler wire (similar to base metal) type B

\begin{tabular}{cccc}
\hline \%C & \%Cr & \%Mo \\
\hline 0.3 & 0.8 & 0.24 \\
\hline
\end{tabular}

Table 4. Chemical analysis of low carbon filler wire type $L$

\begin{tabular}{ccc}
\hline$\% \mathrm{C}$ & \%Cr & \%Mo \\
\hline 0.04 & 1.1 & 0.58 \\
\hline
\end{tabular}

Table 5. Hardness test results (HVN)

\begin{tabular}{cccc}
\hline Sample No. & HAZ & Weld Metal & Base Metal \\
\hline B11 & 267 & 325 & 241 \\
B21 & 260 & 338 & 245 \\
B31 & 222 & 227 & 211 \\
L11 & 270 & 274 & 259 \\
L21 & 265 & 267 & 272 \\
L31 & 220 & 271 & 248 \\
\hline
\end{tabular}

Table 6. Tensile test results

\begin{tabular}{ccc}
\hline Sample No. & \% Elongation & Ultimate Tensile Strength (N/MM2) \\
\hline As rolled 4130 & 23 & 766 \\
As rolled 4130 & 17 & 773 \\
B11 & - & 800 \\
B12 & - & 793 \\
B21 & - & 760 \\
B22 & - & 753 \\
B31 & - & 664 \\
B32 & - & 653 \\
L11 & - & 746 \\
L12 & - & 762 \\
L21 & - & 693 \\
L22 & - & 687 \\
L31 & - & 615 \\
L32 & - & 660 \\
\hline
\end{tabular}


Table 7 depicts impact test results at $-50^{\circ} \mathrm{C}$ for weld metal and heat affected zones (HAZs) which are the average of three samples values. According to the results, there is no considerable difference in weld metal impact test values in the samples. However, heat affected zone impact test results have been dramatically changed. Optimal toughness results belong to pre- and post-heated samples. This is because of the tempering of brittle phases which formed during cooling.

Table 8 illustrates side bend results. Samples without pre/post heat treatment (group 1) and with pre-heat but without post-heat (group 2) fractured when bent more than $34^{\circ}$. However, in both types of filler wires, pre- and post-heated samples could be bent to $180^{\circ}$ without being fractured or cracked. It is worth knowing that failure in weld only can be observed in sample with higher amount of carbon content in filler wire (group B1).

Unlike carbon steels, HSLA steels such as 4130 can be hardened even at a slow cooling rate. Figure 1 shows a CCT diagram of 4130 steel. As alloy elements retard the diffusion, the CCT diagram shifts to the right of the chart. Therefore, depending on cooling rate values, ferrite, remained austenite or martensite can be formed during the cooling. At very slow cooling rates, $2.2^{\circ} \mathrm{C} / \mathrm{Sec}$, ferrite

Table 7. Impact test results in $\left(-50^{\circ} \mathrm{C}\right)$

\begin{tabular}{cccc}
\hline Sample No. & Impact Energy (J) & Sample No. & Impact Energy (J) \\
\hline BW11 & 21 & LW11 & 15 \\
BW12 & 18 & LW12 & 17 \\
BW13 & 19 & LW13 & 6 \\
BH11 & 6 & LH11 & 4 \\
BH12 & 5 & LH12 & 5 \\
BH13 & 5 & LH13 & 16 \\
BW21 & 12 & LW21 & 21 \\
BW22 & 15 & LW22 & 26 \\
BW23 & 20 & LW23 & 8 \\
BH21 & 7 & LH21 & 8 \\
BH22 & 9 & LH22 & 7 \\
BH23 & LH23 & 30 \\
BW31 & 10 & LW31 & 25 \\
BW32 & 15 & LW32 & 20 \\
BW33 & 17 & LW33 & 130 \\
BH31 & 21 & LH31 & 110 \\
BH32 & 133 & LH32 & 125 \\
BH33 & 125 & LH33 & \\
\hline
\end{tabular}

Table 8. Side bend test results

\begin{tabular}{|c|c|c|c|}
\hline Sample No. & Bend Test Result & Sample No. & Bend Test Result \\
\hline B11 & Fracture in HAZ \& weld & L11 & Fracture in $\mathrm{HAZ}$ \\
\hline B12 & Fracture in HAZ \& weld & $\mathrm{L} 12$ & Fractured in HAZ \\
\hline B13 & Fracture in HAZ \& weld & L13 & Fractured in HAZ \\
\hline B14 & Failure in HAZ & L14 & Fractured in HAZ \\
\hline $\mathrm{B} 21$ & Failure in HAZ & L2 1 & Micro crack in HAZ \\
\hline $\mathrm{B} 22$ & Failure in HAZ & L22 & Micro crack in HAZ \\
\hline $\mathrm{B} 23$ & Failure in HAZ & L23 & Micro crack in HAZ \\
\hline B24 & Failure in HAZ & L24 & Bend to $34^{\circ}$ \\
\hline B31 & Bend to $180^{\circ}$ & L31 & Bend to $180^{\circ}$ \\
\hline B32 & Bend to $180^{\circ}$ & L32 & Bend to $180^{\circ}$ \\
\hline B33 & Bend to $180^{\circ}$ & L33 & Bend to $180^{\circ}$ \\
\hline B34 & Bend to $180^{\circ}$ & L34 & Bend to $180^{\circ}$ \\
\hline
\end{tabular}




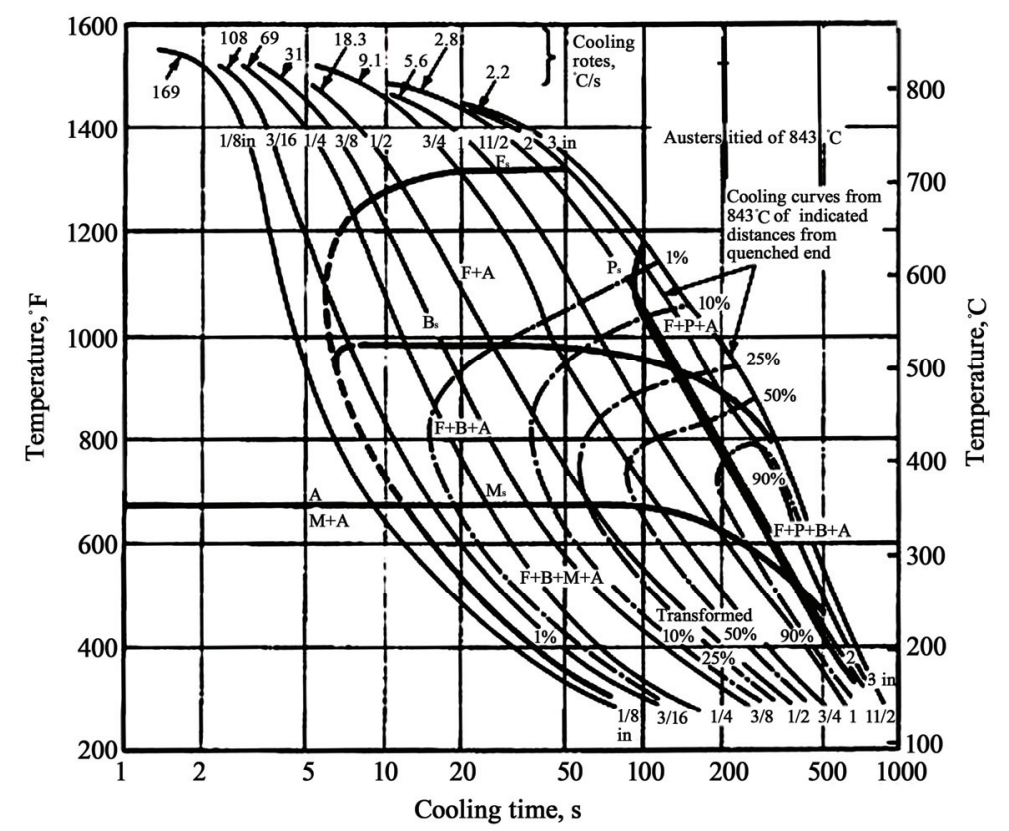

Figure 1. CCT diagram for 4130 steel [17]

and remained austenite can be formed. However, the remained austenite can still find a chance to transform to the upper or lower bainite, depending on the cooling rate at that specific point.

A small and focused weld spot in the GTAW process develops a considerable thermal gradient, which increases the cooling rate by conduction resulting from the heat sink of test plates. Subsequently, depending on the distance from the weld spot, diverse cooling rates result. Hence, a variety of non-equilibrium and brittle phases should be expected in heat affected zones.

With post-heat treatment, brittle phases such as bainite or martensite can be tempered. Hardness results in Table 5 illustrate a $10-12 \%$ drop in hardness values for samples which are post-heated (B31 and L31). Moreover, hardness results show that pre-heating by itself does not cause a considerable change in hardness. The higher hardness of weld metal in group B compared to group L is due to the higher amount of carbon contents in group B.

Carbon content increases the hardness and encourages the brittle phases during the cooling. Therefore, using high carbon filler wire increases the probability of crack formation in weld metal (side bend test results Table 8). Since dilution occurs during welding, alloy elements such as carbon enter the melt pool from the base metal. Thus, weld chemical composition has a higher carbon content compared to the filler wire, which should be taken into account.

\section{Conclusions}

From this article, the following conclusions can be dra- wn: High carbon filler wire, type B (similar to the base me- tal composition), caused more failures in weld metal and fusion boundaries in bend test results.

Low carbon filler wire shows better results in terms of decreasing the risk of crack formation.

Tempered martensite in HAZ resulting from post-weld heat treatment shows valuable results in 4130 steels.

Pre- and post-heat treatments play a crucial role in controlling cooling rates and tempering the formed brittle phases in HAZ, respectively. Post-heat treatment increases the HAZ impact toughness up to 20 times.

\section{REFERENCES}

[1] W. E. Lukens, "Mechanical Properties of HSLA Steel Buried GTAW," proceedings of 67th AWS conference, Atlanta, 1987, pp. 215S-220S.

[2] Lorentz, "Utilization of Quenching and Tempering of HSLA in Heavy Thickness for Welded Construction," Welding Research Supplement, Vol. 5, No. 1, 1962, pp. 433S444S.

[3] T. Bevis and A. Weyenberg, "Best Practice for GTAW 4130 Chrom-Moly," Welding Journal, Vol. 89, No. 4, April 2010, pp. 42-49.

[4] J. A. Todd, L. Chen, E. Y. Yankov and S. Mostovoy, "Crack Closure Effects on Fatigue Crack Growth Thresholds and Remaining Life in an HSLA Steel," Journal of Pressure Vessel Technology, Transactions of the ASME, Vol. 119, No. 1, 1999, pp. 37-44..

[5] J. Fulcer and J. Fogle, "Choose the Correct Filler Rod and Establish a Weld Pool,” Welding Journal, Vol. 86 ,No. 8, 2007, pp. 38-40. 
[6] L. P. Earolino, "The Effect of Carbon Content on the Need to Post Weld Heat Treat Low Alloy Steel Casting," Welding Research Supplement, Vol. 5, No. 1, 1986, pp. 41-46.

[7] W. S. Kyte, "Post Weld Heat Treatment for Hydrogen Removal," Welding Research Supplement, Vol. 2, No. 2, 1979, pp. 54S-58S

[8] J. W. Hooijmians, "A Model of Hydrogen Absorption during GTA Welding," Welding Research Supplement, Vol. 9, No. 5, 1997, pp. 264S-268S.

[9] J. R. Still, "Welding of 4130, 4140, Steels for Drilling Systems," Welding Journal, Vol. 23, No. 2, 1997, pp. 37- 41.

[10] L. W. Tsay, Y. M. Li, C. Chen and S. W. Cheng, "Mechanical Properties and Fatigue Crack Growth Rate of Laser Welded," Journal of Fatigue, Vol. 14, No. 4, 1992, pp. 239-247.

[11] S. Ravi, V. Balasubramanian and N. Nemat, "Influence of Post Weld Heat Treatment on Fatigue Life Prediction of Strength Mismatched HSLA Steel Welds," Journal of Fatigue, Vol. 27, No. 5, May 2005, pp. 547-553.
[12] H. Bultel and J. Vogt, "Influence of Heat Treatment on Fatigue Behavior of 4130 AISI Steel," Journal of Fatigue, Vol. 2, No. 1, 2010, pp. 917-924.

[13] P. Macelino and H. Voorwald, "Considerations about the Welding Repair Effects on the Structural Integrity of an Airframe Critical to the Flight-Safety," Journal of $\mathrm{Fa}$ tigue, Vol. 2, No. 1, 2010, pp. 1895-1903.

[14] O. M. Akselen, "Assessment and Predications of HAZ Tensile Properties of HSLA," Welding Research Supplement, Vol. 7, No. 3, 1989, pp. 362S-365S.

[15] R. E. Monley, "Evaluation of Various Filler Wire Compositions for GTA Welding of Low Alloy Steels," Welding Research Supplement, Vol. 3, No. 2, 1980, pp. 12S-135S.

[16] S. C. Ernst, "Weld Ability of High Strength Low Expander Supper Alloy," Welding Research Supplement, Vol. 7, No. 4, 1989, pp. 418S-424S.

[17] T. V. Philip, "Steel Products," ASM, New York, 1995, pp. 421-423.

[18] Data Base of Steel Transformation Diagrams, 2009. 